\title{
Keratoconus: current perspectives
}

This article was published in the following Dove Press journal:

Clinical Ophthalmology

I) October 2013

Number of times this article has been viewed

\section{Jayesh Vazirani \\ Sayan Basu}

Cornea and Anterior Segment Services, LV Prasad Eye Institute, Hyderabad, India
Correspondence: Sayan Basu Sixth Floor, LV Prasad Eye Institute, Kallam Anji Reddy Campus, Banjara Hills Road No 2, Hyderabad, 500034, India Tel +9| 9989479969

Fax +9| 402354 827|

Email sayanbasu@lvpei.org
Abstract: Keratoconus is characterized by progressive corneal protrusion and thinning, leading to irregular astigmatism and impairment in visual function. The etiology and pathogenesis of the condition are not fully understood. However, significant strides have been made in early clinical detection of the disease, as well as towards providing optimal optical and surgical correction for improving the quality of vision in affected patients. The past two decades, in particular, have seen exciting new developments promising to alter the natural history of keratoconus in a favorable way for the first time. This comprehensive review focuses on analyzing the role of advanced imaging techniques in the diagnosis and treatment of keratoconus and evaluating the evidence supporting or refuting the efficacy of therapeutic advances for keratoconus, such as newer contact lens designs, collagen crosslinking, deep anterior lamellar keratoplasty, intracorneal ring segments, photorefractive keratectomy, and phakic intraocular lenses.

Keywords: keratoconus, corneal topography, hydrops, collagen cross-linking, keratoplasty, contact lenses

\section{Introduction}

Descriptions of a conical cornea have existed in the literature for close to three centuries. In a recent review, Grzybowski and McGhee have meticulously traced observations of various authors through the 18th and 19th centuries, including what is probably the earliest written description of keratoconus by Benedict Duddell. ${ }^{1}$ John Nottingham, however, is credited with providing the first comprehensive understanding of this condition through his landmark treatise published in $1854 .^{2}$ The insights provided by Sir William Bowman and the subsequent evolution of ophthalmic literature on keratoconus have been documented in another review. ${ }^{3}$ The arrival of sophisticated tools for mapping the contours of the cornea and advances in treatment, promising structural and functional betterment of the keratoconic eye, have resulted in an overwhelming interest in the condition in recent years. This is reflected in the explosion of scientific literature on the subject in the past two decades.

\section{Nomenclature}

Keratoconus is characterized by progressive corneal protrusion and thinning, leading to irregular astigmatism and impairment of visual function (Figure 1). In its most obvious form, it is easy to recognize, and a diagnosis of clinically evident keratoconus is rarely disputed. There exists considerable confusion, however, about appropriate labeling of eyes with subtle signs suggestive of ectasia apparent only on corneal topography. Keratoconus is essentially a bilateral condition, though presentation 


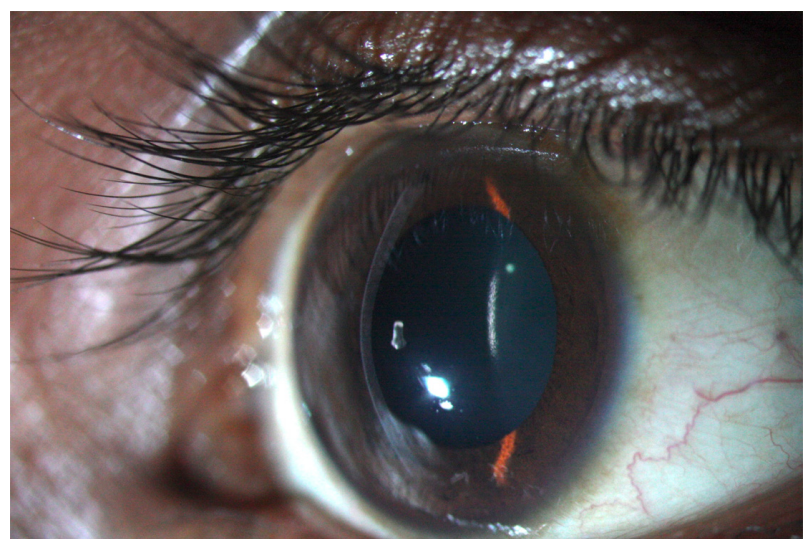

Figure I Slit-lamp photograph of an eye with keratoconus demonstrating increased corneal curvature (ectasia).

may be markedly asymmetric. It may take years after the initial diagnosis of keratoconus in one eye for the condition to become apparent in the fellow eye. ${ }^{4}$ It has been suggested that the term "forme fruste keratoconus" be used for such less affected fellow eyes that display no clinical findings except certain topographic changes. In contrast, the term "keratoconus suspect" should be reserved for eyes with suspicious topographic patterns, wherein the fellow eye of the individual does not have keratoconus. ${ }^{5}$

\section{Epidemiology, genetics, and etiology}

Epidemiologic data on keratoconus is derived mostly from hospital-based studies. It is a bilateral disease, with no gender predominance. The reported incidence ranges from 1.3 to 25 per 100,000 per year across different populations, and a prevalence of $8.8-229$ per $100,000 . .^{3,6-10}$ Two of these studies reported a significantly higher incidence and prevalence in Asians compared with whites, suggesting the influence of ethnicity on the disease. ${ }^{8,9}$ The onset of keratoconus is generally during puberty, with a variable amount of progression, which may last until the third or fourth decade of life, when the corneal shape generally becomes stable. The Collaborative Longitudinal Evaluation of Keratoconus study prospectively studied 1,209 patients with keratoconus, with annual examinations for 8 years. The authors found a decrease in high-contrast and low-contrast visual acuity and progressive steepening of the cornea in the study subjects. The incidence of corneal scarring was $20 \%{ }^{11}$

Disease associations include atopy, vernal keratoconjunctivitis (Figure 2), retinitis pigmentosa, Leber congenital amaurosis, eye rubbing, hard contact lens wear, mitral valve prolapse, Down syndrome, and noninflammatory connective tissue disorders, such as Ehlers-Danlos syndrome, and

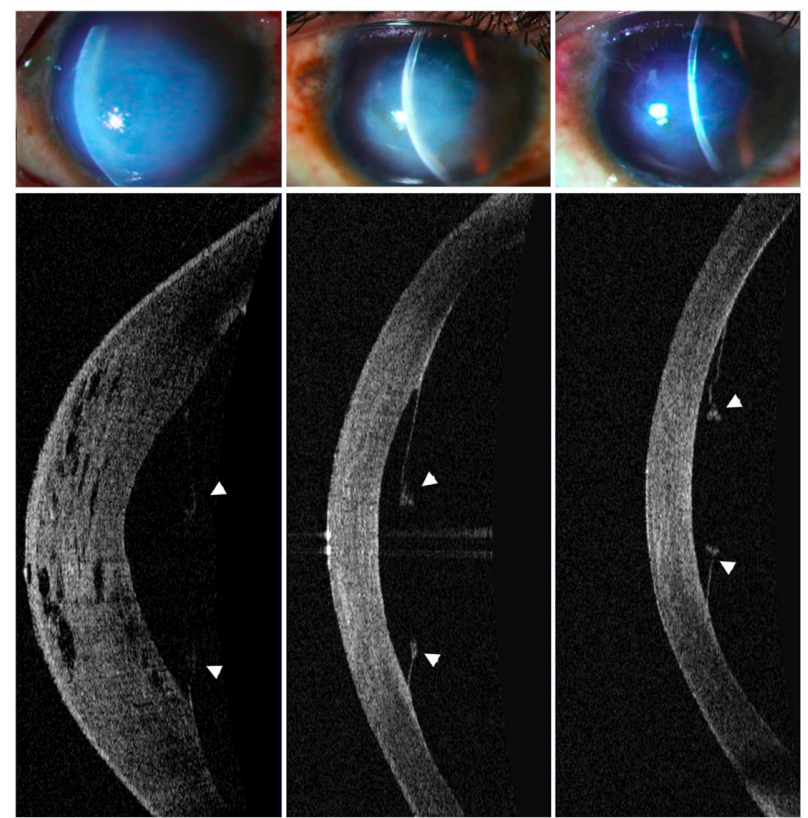

Figure 2 Slit-lamp and anterior segment optical coherence tomographic images of the right eye of a 16-year-old boy with atopy, vernal keratoconjunctivitis, and advanced keratoconus who presented with acute corneal hydrops after an episode of severe eye-rubbing. Corneal edema decreased gradually from presentation (left panel, day 18 after onset of corneal hydrops) to 2 months (middle panel) and 4 months (right panel) thereafter. The patient was treated conservatively with topical steroids and hyperosmotic eye drops. The break and persistent detachment of the Descemet's membrane (white arrowheads) is clearly discernible on anterior segment optical coherence tomographic imaging.

osteogenesis imperfecta. ${ }^{3,7,12-22}$ A cause and effect relationship is often difficult to establish. Some associations may point towards a common genetically determined cause; others may potentially cause corneal ectasia by recurrent mechanical trauma. It does, however, make sense to look for evidence of systemic atopic disease or signs of ocular allergy in patients with keratoconus. Conversely, patients with a diagnosis of Down syndrome or noninflammatory connective tissue disease coming for an eye examination should be carefully examined for signs of keratoconus.

A genetic basis for keratoconus has been suspected due to clustering of cases within families as well as high concordance in monozygotic twins. A number of linkage studies and a few association studies have been performed to investigate several candidate genes, including those coding for different types of collagen and proteinase inhibitors as well as antioxidant genes and genes belonging to the homeobox family. ${ }^{23}$ Multiple studies have rarely identified the same loci as being related to keratoconus. Again, no mutations in any genes have been identified in the multiple loci mapped in familial keratoconus. ${ }^{24}$ The multitude of loci implicated in keratoconus suggests that more than simple Mendelian genetics may be involved. 
Keratoconus has conventionally been held to be a noninflammatory condition. Studies on tear film and serum cytokines, enzyme levels, and tear proteomics have challenged this view in recent years. Jun et al studied levels of multiple cytokines in the tear film and sera of subjects with keratoconus as well as controls. They found no difference in serum levels of cytokines between keratoconus and control subjects, confirming the belief that keratoconus is not associated with major systemic inflammation. Levels of interleukin (IL)-6 and IL-17 were increased, while those of IL-12, tumor necrosis factor alpha, CCL5, and IL-13 were decreased in keratoconus compared with control tear fluids. The authors suggest that, rather than a global increase in proinflammatory cytokines in eyes with keratoconus, it is a complex imbalance between proinflammatory and anti-inflammatory molecules that disrupts the corneal homeostasis. ${ }^{25}$ Balasubramanian et al, in a recent review, concluded that levels of matrix metalloproteinases are altered in keratoconic corneas. ${ }^{26}$ The same group also studied tear film proteomics, and found decreased levels of total protein, lactoferrin, and secretory $\operatorname{IgA}$ in keratoconus compared with control tears. ${ }^{27}$

The consensus thus far is that keratoconus is likely to be a multifactorial, multigenic disorder with complex inheritance patterns, and environmental factors probably play an equally important role in disease causation. A "two-hit" hypothesis is favored by many, postulating that an environmental insult (such as eye-rubbing) may be needed in addition to a genetic susceptibility to the disease.

\section{Clinical features}

A typical patient with keratoconus presents in the teens or early twenties with complaints of blurring or distortion in vision and having to change glasses frequently due to changes in refractive error. Retinoscopy usually shows irregular myopic astigmatism. A scissoring reflex and an "oil-droplet" reflex (Charleux sign) are highly suggestive of keratoconus. Prominent corneal nerves on slit-lamp examination should prompt a search for other signs of keratoconus. Corneal ectasia is accompanied by thinning, which is generally greatest at the apex of the cone (Figures 1 and 3). Subepithelial and anterior stromal scars may be present, secondary to breaks in Bowman's membrane. Vogt's striae are fine parallel lines seen in the posterior stroma (Figure 4); these disappear on application of pressure on the globe. Fleischer's ring is formed due to deposition of hemosiderin, found around the base of the cone and best appreciated through a cobalt blue filter (Figure 5). Gross clinical signs in advanced keratoconus

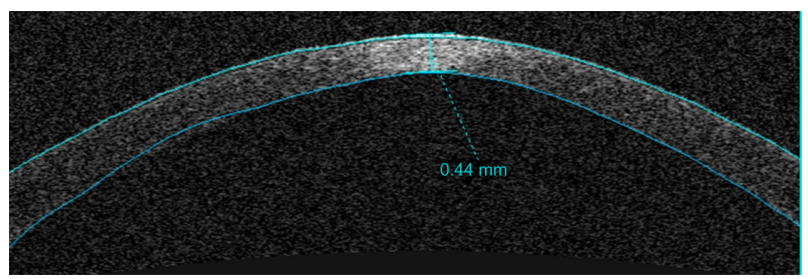

Figure 3 Anterior segment optical coherence tomography image of an eye with keratoconus, demonstrating central thinning of the cornea.

include V-shaped distortion of the lower eyelid in down gaze due to an excessively protuberant conical cornea, known as Munson's sign, and a sharply focused light beam near the nasal limbus produced by lateral corneal illumination (Rizzuti's sign). Acute hydrops is a specific presentation of keratoconus caused by sudden breaks in Descemet's membrane (DM), (Figure 2). A sudden decrease in vision is accompanied by corneal clouding. Corneal edema with or without intrastromal clefts or blebs is seen overlying the break. $3,7,28$

\section{Imaging}

Keratometry using a manual keratometer (Javal-Schiotz or Bausch and Lomb type) may show a steep cornea, high astigmatism, and/or distorted mires in keratoconus. This can be used as a simple, inexpensive imaging device. Computerized videokeratography for diagnosis of keratoconus was first introduced in the 1980s..$^{29}$ Early systems relied on analysis of Placido disk images to compute anterior corneal curvature. A zone of increased corneal power surrounded by zones of decreasing corneal power, inferior-superior asymmetry in corneal power, and skewing of the steepest radial axes above and below the horizontal meridian were established as characteristics of keratoconus on videokeratography maps. A variety of indices were developed for discriminating

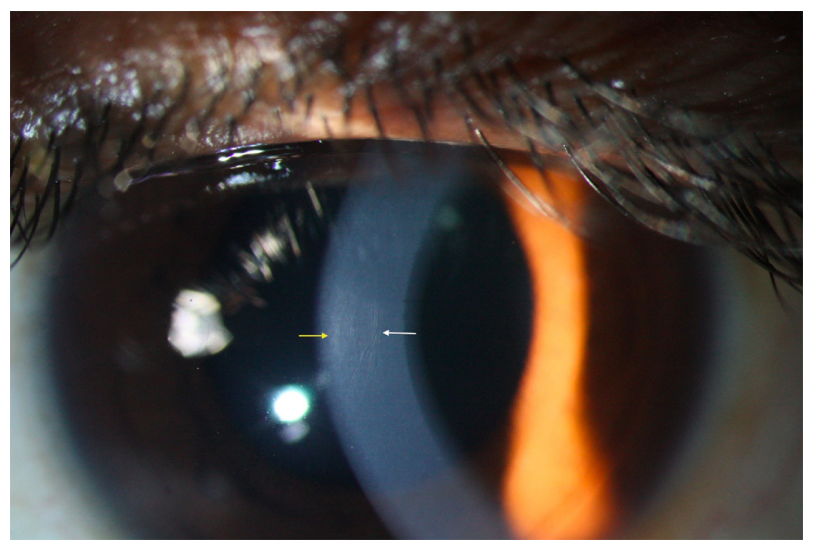

Figure 4 Slit-lamp photograph of the same eye as in Figure 3, showing apical scarring (yellow arrow) and Vogt's striae (white arrow). 


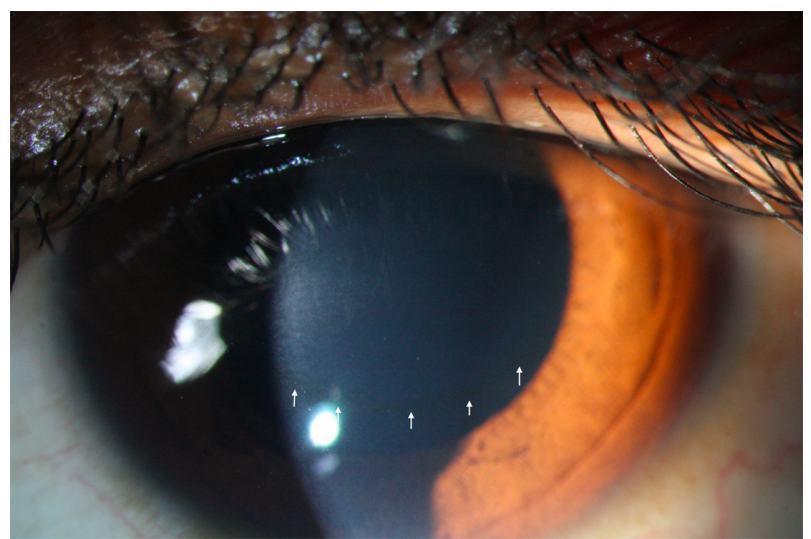

Figure 5 Slit-lamp photograph of the same eye as in Figures 3 and 4, showing Fleischer's ring (white arrows).

keratoconus from normal eyes as well as other conditions. Some of the popular ones included the keratoconus prediction index from the Klyce-Maeda group and the KISA index by the Rabinowitz group. ${ }^{30-34}$ These indices have been utilized to detect subtle anomalies and follow disease progression in clinically normal appearing eyes of unaffected relatives of patients with keratoconus as well as in fellow eyes of apparently unilateral keratoconus patients. ${ }^{4,35}$

The advent of refractive surgery in the 1990s and the coincident risk of iatrogenic ectasia or unmasking of keratoconus spurred the development of newer diagnostic devices aimed at early detection of subclinical keratoconus. The Orbscan (Bausch and Lomb, Rochester, NY, USA) utilized slit scanning technology to provide wide-field pachymetry and anterior and posterior elevation as well as keratometry maps. A later iteration, the Orbscan II, combines slit scanning with Placido-based topography analysis. This has been shown to be more sensitive than earlier devices for detection of keratoconus. Maximum posterior elevation compared with the best fit sphere (BFS), irregularity in the central $3 \mathrm{~mm}$ and $5 \mathrm{~mm}$ zones as well as pachymetry have been found to be useful in discriminating keratoconus suspects from normal subjects. ${ }^{36}$ Increase in apex elevation, displacement of the corneal apex, decrease in thinnest-point pachymetry, and an increase in the mean simulated keratometry minimum value have been documented on serial analysis in progressive keratoconus (Figure 6). ${ }^{37}$

The Scheimpflug principle has been exploited in corneal tomographers such as the Pentacam (Oculus, Wetzlar, Germany) to provide three-dimensional mapping of the cornea, including direct measurement of anterior and posterior corneal surfaces, pachymetry, as well as anterior chamber angle characterization. A much touted feature of the Pentacam is the Belin/Ambrosio-enhanced ectasia display, which excludes a $4 \mathrm{~mm}$ zone centered on the thinnest portion of the cornea from the reference shape calculation. The resulting "enhanced BFS" is supposed to approximate a normal cornea closely, making subtle elevations more pronounced and possibly aiding in detection of early or subclinical keratoconus. Various indices in normal eyes, keratoconus suspects, as well as established keratoconus have been measured, although definite superiority over earlier devices is yet to be proven. ${ }^{38-43}$ Recent interest has focused on characterization of aberrometry profiles as well as understanding of corneal biomechanics in keratoconus using instruments such as the Ocular Response Analyzer (Reichert Inc, Depew, NY, USA). Compared with controls, keratoconic eyes have been found to have excessive higher order aberrations and lower values of corneal hysteresis and corneal resistance factor. ${ }^{44-48}$

\section{Pathology}

Numerous studies have investigated the pathologic changes in keratoconic corneas. Sherwin et al have summarized the changes in different layers of the cornea in keratoconus. ${ }^{49}$ The epithelium shows central thinning, with irregular or thickened basement membrane and defects in Bowman's layer. Stromal scarring and cells have been identified in proximity to these breaks, with evidence of apoptosis. ${ }^{50,51}$ In vivo confocal microscopy has demonstrated decreased sub-basal nerve density correlating with decreased corneal sensation, and basal epithelial density. ${ }^{52}$ There is loss of stromal collagen lamellae and altered collagen fibril orientation. Decreased keratocyte density, particularly in the central anterior stroma, has been reported. ${ }^{53} \mathrm{DM}$ and endothelium are generally unaffected, except in cases with hydrops. Endothelial changes reported in a small percentage of cases include pleomorphism and elongation of cells. ${ }^{7}$ Features of corneal hydrops seen on histopathology, and more recently using anterior segment optical coherence tomography, include epithelial and stromal edema, intrastromal fluid clefts, and changes in the DM (Figure 2). The DM can show detachment from the stroma with or without breaks and flat or rolled ends. ${ }^{54,55}$

\section{Management Optical correction}

In early stages, the refractive error in keratoconus can be managed by spectacle use. As the disease advances, the changes in corneal shape and consequent irregular astigmatism result in suboptimal visual quality with spectacles, necessitating use of contact lenses. Early on, soft or soft toric contact lenses made from materials such as hydrogel or silicone hydrogel may be adequate for providing clear vision. Advantages are 
a Oorbscan

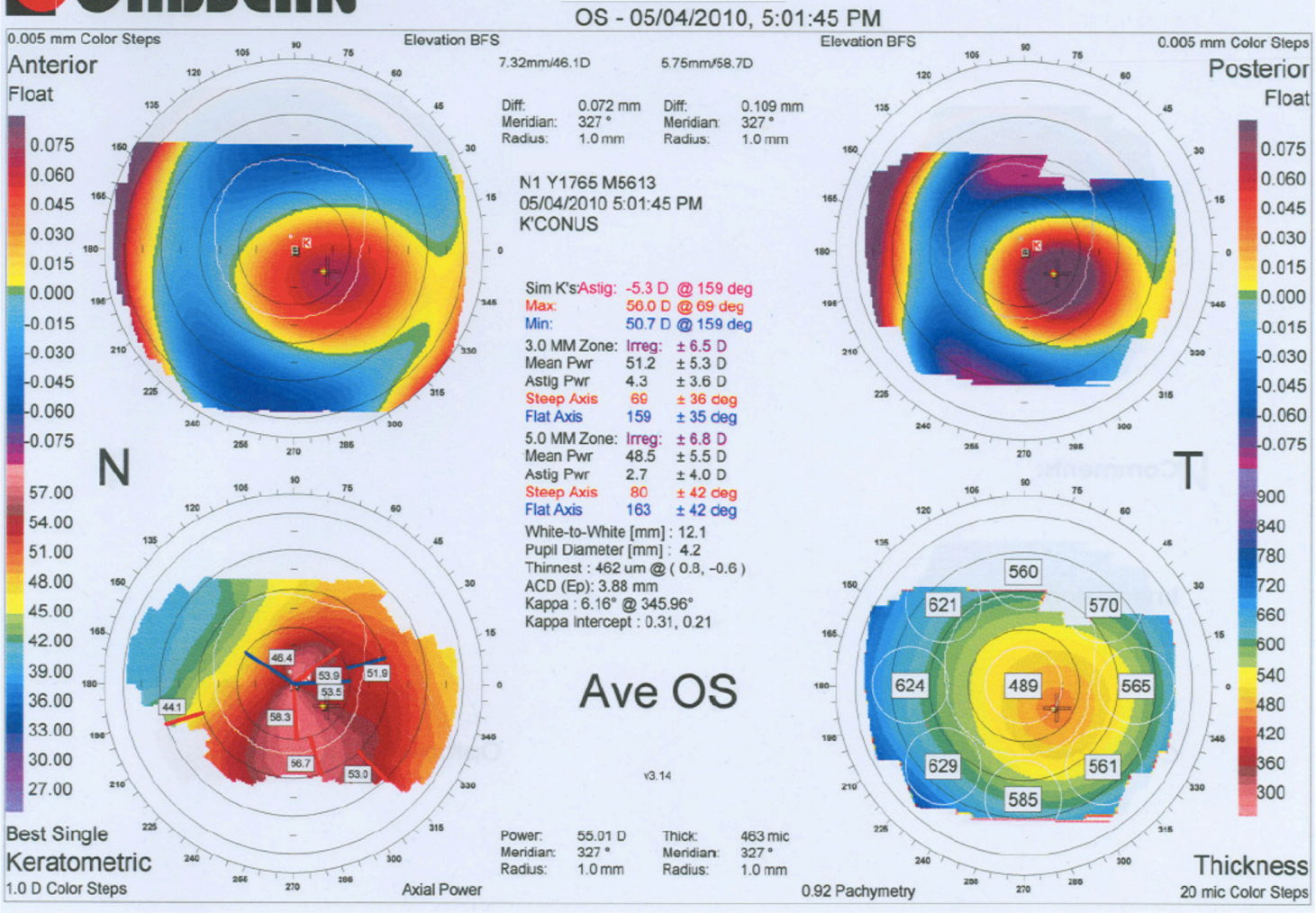

${ }^{\text {B Dorbscan }}$

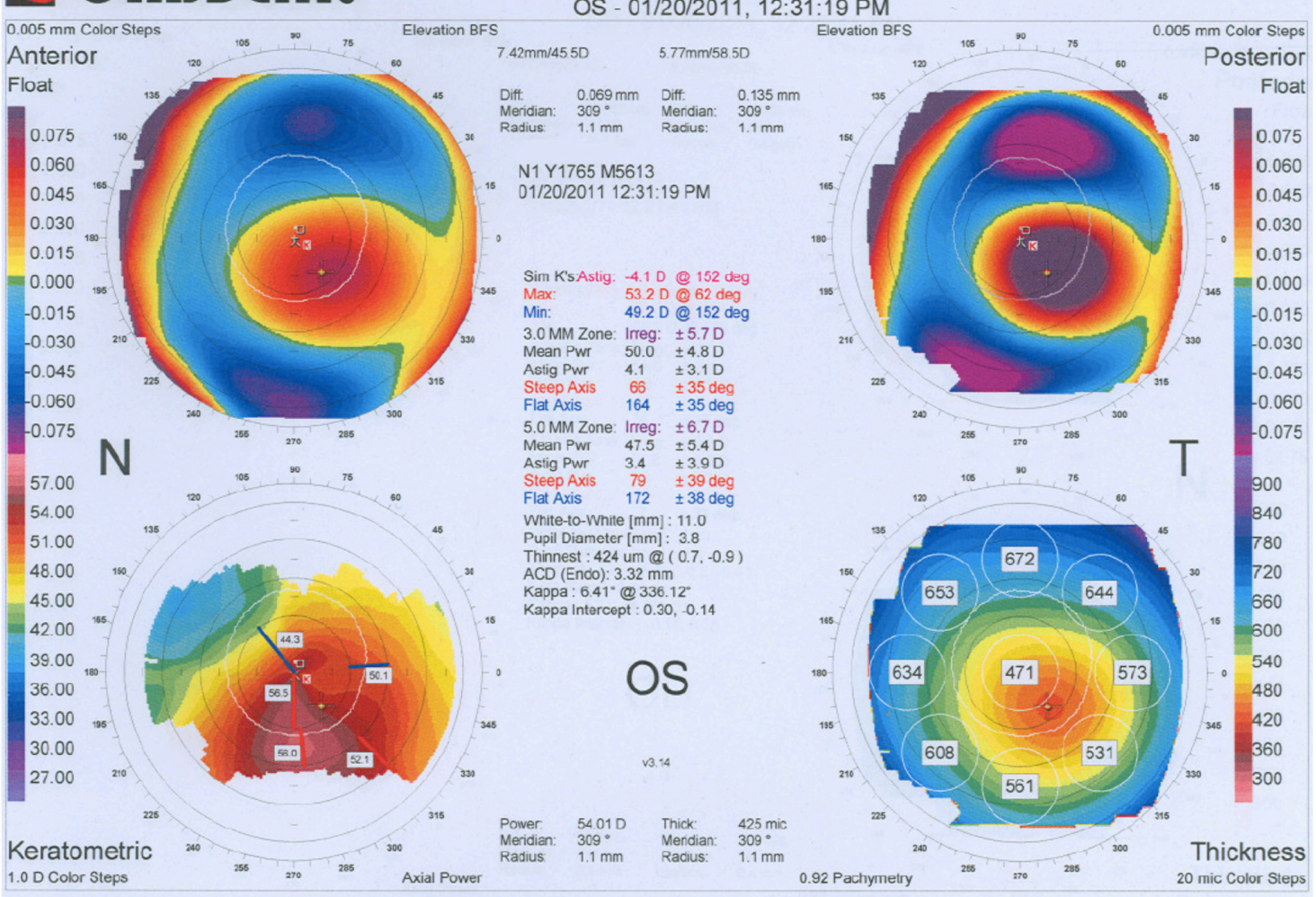

Figure 6 Tomography maps (Orbscan Ilz, Bausch and Lomb, Rochester, NY, USA) before (A) and 9 months after (B) collagen crosslinking showing flattening of corneal surface. Maximum and minimum simulated keratometry values show a decrease of 2.8 and 1.5 diopters, respectively. 
good comfort and lower cost. By and large, however, rigid gas permeable lenses are required, and are the most commonly used contact lens type in keratoconus. In two large, prospective, observational studies on keratoconus conducted in the US and Scotland, rates of rigid gas permeable contact lens use were $65 \%$ and $91 \%$, respectively. ${ }^{11,56}$ Multiple lens designs and fitting options are available, and achieving a satisfactory fit is often a painstaking process. Rigid gas permeable lenses mask the underlying corneal shape abnormality and provide good tear exchange, but may be uncomfortable to wear. A popular design is the Rose $\mathrm{K}$ lens (Menicon Co, Ltd, Nagoya, Japan). Moderate keratoconus may require the use of intralimbal rigid gas permeable lenses or miniscleral lenses. Very advanced cases with large, decentered cones, dry eye, or discomfort with conventional lenses may be corrected with the use of scleral lenses. Other options include piggyback lenses and hybrid lenses. The logistics and cost associated with use of these lenses often makes them an impractical choice. ${ }^{29,57}$

\section{Collagen crosslinking}

As understanding of the pathology and pathogenesis of keratoconus has evolved, so have efforts to favorably modify the biology of the keratoconic cornea. Spoerl et al first tested the effects of a combination of riboflavin used as a photosensitizer and ultraviolet light to crosslink corneal collagen in laboratory experiments. Increase in corneal rigidity and Young's modulus was reported in vitro in both porcine and human corneas. . $8,59^{-5}$ This was followed by the results of the first pilot clinical trial carried out by Wollensak et al in Dresden. At a follow-up ranging from 3 to 47 months, progression of keratoconus was stopped in all 23 treated eyes. A mean reduction of 2.01 diopters in maximal keratometry and 1.14 diopters in refractive error was observed in the 16 eyes that showed regression. ${ }^{60}$ The procedure is claimed to be the only one capable of altering the natural history of keratoconus.

Subsequently, collagen crosslinking has been enthusiastically incorporated into practices worldwide. Published reports consist mostly of case series. Results indicate that some degree of flattening or stabilization of the corneal surface, as measured by topography, occurs in a majority of eyes (Figure 6A and B). Change in refractive error is less impressive, and does not correspond to the change in keratometric values. ${ }^{61-64}$

Surprisingly, even a decade after the initial reports, well designed randomized controlled trials on collagen crosslinking are scarce. Wittig-Silva et al reported preliminary results, showing a halt in keratoconus progression at 12 months in treated eyes. However, less than a third of enrolled eyes completed the 12-month follow-up. ${ }^{65}$ Hersh et al used a somewhat complicated study design in a trial conducted to obtain approval for collagen crosslinking from the US Food and Drug Administration. Eyes in the sham treatment group were used as controls only for 3 months, after which they crossed over to the treatment group and underwent crosslinking. Another fellow-eye control group ranged from eyes with frank keratoconus to eyes with no evidence of disease. At one year, there was a 2-diopter decrease in maximum keratometry and a 1.5-diopter decrease in average keratometry in treated eyes with keratoconus. Interestingly, there were no changes in visual acuity, keratometry, or refraction in the control group eyes at one year, indicating no progression of disease. ${ }^{66}$

O'Brart et al reported 18-month postoperative results in 22 treated eyes, using fellow-eyes for comparison. No eyes in the treatment group and three eyes in the control group showed evidence of progression. ${ }^{67}$ The advanced age of the patients studied, use of refraction as a criterion to assess disease progression, a questionable difference in the progression rates in the two groups, and lack of sample size calculation are some of the limitations of this study ${ }^{68}$

Reported adverse effects with collagen crosslinking include bacterial, fungal, acanthamoeba, and sterile keratitis. ${ }^{69-75}$ Kymionis et al reported significant endothelial cell loss after crosslinking in thin corneas. ${ }^{76}$ Spoerl et al have described safety-related guidelines to be followed during the crosslinking procedure. These include epithelial removal, application of $0.1 \%$ riboflavin solution for 30 minutes before ultraviolet exposure, a homogenous ultraviolet irradiance of $3 \mathrm{~mW} / \mathrm{cm}^{2}$ with a wavelength of $370 \mathrm{~nm}$, and a minimal corneal stromal thickness of $400 \mu \mathrm{m}$. Damage to the endothelium, lens, or retina is not expected if these criteria are fulfilled. ${ }^{77}$ Of great concern are reports of persistent corneal edema and corneal decompensation, along with signs of damage to anterior segment structures following crosslinking in concordance with established protocols and guidelines. ${ }^{78-80}$ Modifications to the original Dresden protocol include use of hypo-osmolar riboflavin to swell thin corneas artificially, transepithelial crosslinking using different compounds designed to improve riboflavin penetration or using iontophoresis, and attempts to reduce overall duration of the procedure by increasing ultraviolet radiance..$^{76,81-86}$ The safety and efficacy of these modifications is unproven.

In summary, collagen crosslinking as a means for halting keratoconus progression is definitely backed by a degree of evidence from laboratory and clinical studies. Better designed, prospective, randomized clinical trials with 
watertight case definitions, appropriate outcome measures, sufficient follow-up, and objective means of assessment would be welcome. A search for Phase II and III trials on clinicaltrials.gov shows multiple ongoing studies that hold promise. Currently, there is no consensus on what constitutes "progression" in keratoconus. This opens up potential for abuse in the form of unwarranted procedures. Pertinently, there are no data available showing that collagen crosslinking reduces the need for keratoplasty, improves or maintains contact lens tolerance, or is perceived to be beneficial by recipients of the procedure. Our understanding of keratocyte turnover in the cornea suggests that the effect of crosslinking may be transient. In view of reported adverse effects, we recommend strict adherence to pachymetry guidelines and crosslinking protocols proven to be safe. Expected benefits and potential risks should be clearly discussed with patients, enabling them to make an informed choice.

\section{Keratoplasty}

Generally accepted indications for keratoplasty in keratoconus are poor visual acuity with contact lenses, contact lens intolerance or inability to fit/wear contact lenses, and nonresolving corneal hydrops. The percentage of patients with keratoconus eventually requiring keratoplasty varies widely in different reports. ${ }^{6,87-89}$ The large, prospective, multicenter, Collaborative Longitudinal Evaluation of Keratoconus study reported a $12 \%$ rate of keratoplasty over an 8-year follow-up period. Younger age, steeper keratometry, poorer visual acuity, corneal scarring, contact lens discomfort, and poorer vision-related quality of life were identified with a higher likelihood of keratoplasty. ${ }^{89}$ For quite a few decades, penetrating keratoplasty has been successfully used for visual rehabilitation in keratoconus. Reasonably good visual and refractive outcomes with low complication rates have been consistently reported..$^{90-93}$ Keratoconus is amongst the best indications for doing a penetrating keratoplasty, with long-term graft survival rates surpassing those for any other indication. ${ }^{94-96}$ The 2012 report of the Australian corneal graft registry shows a mean survival of over 18 years for penetrating keratoplasty done for keratoconus. The graft survival rates at 1, 5, 10, 15, and 20 years, respectively, are 97\%, 95\%, 89\%, 77\% and $46 \%$. Graft survival is largely unaffected by recipient age. A second graft done for keratoconus has a mean survival of over 12 years; third and subsequent grafts have a mean survival of over 9 years. Survival rate for grafts done for keratoconus with hydrops is $92 \%$ at one year, but falls to $64 \%$ at 10 years. Grafts done for keratoconus with Down syndrome do much worse, with $77 \%$ survival at one year and $53 \%$ at 10 years. $^{96}$

Microkeratome-assisted lamellar keratoplasty has been tried with varying degrees of success in keratoconus. Busin et al reported optical and refractive outcomes comparable with penetrating keratoplasty in 50 eyes. ${ }^{97}$ The same group has recently published outcomes of a modified microkeratomeassisted lamellar keratoplasty technique. To negate the excessive steepening and irregularity of the final corneal contour induced by the residual recipient stroma, a smaller diameter full-thickness trephination of the recipient bed was carried out before suturing in the donor graft. Results of the first 100 procedures show acceptable outcomes in terms of graft clarity, visual acuity, astigmatism, and endothelial cell loss. Notable complications included buttonholing of the recipient bed necessitating conversion to penetrating keratoplasty and double anterior chamber formation. ${ }^{98}$ The procedure seems attractive because it does not seem to require exceptional surgical skill, has the potential to be standardized, and may provide outcomes similar to penetrating keratoplasty, without the risk of endothelial rejection.

In recent years, deep anterior lamellar keratoplasty (DALK) has emerged as an attractive alternative to penetrating keratoplasty for keratoconus. Unlike penetrating keratoplasty, DALK is not a full-thickness corneal replacement procedure. The epithelium and stroma of the host cornea, preferably up to the DM, are removed, thereby preserving native endothelium. This can be achieved either by manual dissection or by a "big bubble" technique, which uses an air bubble to dissect the plane between corneal stroma and the DM. $\cdot{ }^{99,100}$ A donor cornea with the DM stripped off is then sutured on like a penetrating keratoplasty. DALK has the advantages of essentially being an extraocular procedure and retaining the host endothelium, thereby obviating the risk of endothelial graft rejection and probably improving graft survival. The surgery is technically challenging to perform, has a significant learning curve, and demands greater operating time compared with penetrating keratoplasty. Complications include intraoperative DM perforation, which may necessitate conversion to penetrating keratoplasty, postoperative DM detachment, and interface haze. Also, baring of the DM may not be possible in cases with deep stromal scarring or prior hydrops, resulting in suboptimal visual outcomes due to retained stroma. Nonetheless, pre-descemetic DALK may be a good alternative to penetrating keratoplasty in such cases. ${ }^{101}$

Although very long-term follow-up for DALK is unavailable at present, comparisons indicate that outcomes are similar to penetrating keratoplasty in terms of visual 
acuity and astigmatism, with about $80 \%$ of patients achieving a best-corrected visual acuity of 20/40 or greater in most series. Endothelial cell loss is markedly lower. ${ }^{102-107}$ A technology assessment by the American Academy of Ophthalmology concluded that DALK is equivalent to penetrating keratoplasty in terms of refractive error, and is superior for preservation of endothelial cell density. ${ }^{108} \mathrm{We}$ believe that wherever feasible, DALK should be performed as the standard of care surgery when keratoplasty is required in keratoconus.

\section{Other surgeries}

Symptomatic treatment of acute corneal hydrops is with patching or bandage contact lenses, topical cycloplegic agents, and hypertonic saline. Intracameral perfluoropropane $\left(\mathrm{C}_{3} \mathrm{~F}_{8}\right)$ gas in a nonexpansile concentration of $14 \%$ has been found to significantly reduce the time to resolution of hydrops. ${ }^{109}$ However, the final visual acuity is not affected. The main complication is pupillary block, which is usually reversible. ${ }^{109}$ Imaging may help in deciding which cases are best suited for this procedure, with very large DM breaks visualized on anterior segment optical coherence tomography being a relative contraindication. $.55,110$

Intracorneal ring segments such as Intacs (Addition Technologies, Sunnyvale, CA, USA) and Ferrara rings (Mediphacos, Belo Horizonte, Brazil) are segments made of inert material such as polymethyl methacrylate and acrylic polymers. Originally designed for myopia correction, they are now mainly used in mild to moderate keratoconus to improve contact lens tolerance. Prerequisites include nonprogressive keratoconus, an absence of significant central corneal scarring, and a minimum pachymetry of $450 \mu \mathrm{m}$ at the site of implantation. They are inserted deep into the corneal stroma to achieve central flattening of the surface, using channels created mechanically or by means of a femtosecond laser. Most clinical studies report an improvement in best-corrected visual acuity, with a flattening of the cornea by $2-3$ diopters. Thus, the clinical spectrum within which these devices are useful is limited. Quality of vision may not be improved much in early cases or in those with a good contact lens fit, and their utility in advanced keratoconus cases is doubtful. Major complications include corneal perforation, erosion, infection, corneal haze, neovascularization, melting, and loss of visual acuity. ${ }^{111,112}$

Spherical as well as toric implantable collamer lenses (ICLs) have been used in cases of nonprogressive keratoconus to decrease the spherical and cylindrical refractive error, leading to an improvement in uncorrected visual acuity.
Angle closure disease and diseased corneal endothelium are absolute contraindications to the use of ICLs. Eyes with high irregular astigmatism may not be suitable for toric ICL implantation, as calculation of axis of placement is difficult, and the induced higher order aberrations may lead to unpredictable results. Reports indicate that, for well chosen cases, ICLs are safe and effective for improving uncorrected visual acuity. ${ }^{113-116}$ Other designs that have been utilized include iris supported and iris-claw phakic intraocular lenses. ${ }^{117-119}$ Major concerns include potential for glaucoma, iritis, and cataract formation.

Cataract surgery in eyes with keratoconus can be challenging, due to difficulty in accurate intraocular lens (IOL) power calculation and correction of astigmatism. The SRK-II formula has been found to provide predictable IOL power calculation compared with other formulae in mild keratoconus. For moderate and advanced keratoconus, predictability in IOL power calculation is much less, and no particular formula seems to provide an advantage over another. ${ }^{120}$ Due to irregular corneal shape and decentered apex in keratoconus, use of keratometry readings based on topography or raytracing technology as well as optical measurement of axial length have been recommended. ${ }^{121}$ Toric IOLs may be used to provide good uncorrected postoperative visual acuity after cataract surgery in an eye with keratoconus and high regular corneal astigmatism. ${ }^{122,123}$ It seems prudent to avoid cases with irregular astigmatism, because the induced higher order aberrations may severely compromise the quality of vision with toric IOLs.

Evidence of corneal ectasia is conventionally held to be a contraindication for excimer laser-based refractive surgery. Recently, there has been a surge of interest in photorefractive keratectomy for refractive error correction in keratoconus. Studies have reported good outcomes of photorefractive keratectomy in keratoconus suspect eyes, with excellent uncorrected visual acuity and predictable refractive outcome in a majority of eyes. One study has also examined the results of photorefractive keratectomy in eyes with keratoconus. None of these studies report progression of ectasia after the procedure. ${ }^{124-127}$ Results need to be interpreted with caution, because not all included cases seem to be representative of keratoconus. It is suggested that topography-guided ablation may be the best choice for such cases. ${ }^{128}$ Topography-guided conductive keratoplasty has been proposed as a means of reshaping the cornea in advanced cases of keratoconus. ${ }^{129}$ The study design and methodology have been questioned, and larger series are needed to confirm the utility of this modality. ${ }^{130}$ 
In recent times, a spate of combinations of procedures, such as collagen crosslinking, intracorneal rings, ICLs, and photorefractive keratectomy have been reported. Maximum interest seems to be focused on combining collagen crosslinking with photorefractive keratectomy. Same day collagen crosslinking combined with topography-guided photorefractive keratectomy has been found to be superior to sequential procedures for visual rehabilitation. ${ }^{131}$ Similar reports have documented a significant decrease in refractive error as well as refractive stability after collagen crosslinking combined with photorefractive keratectomy. ${ }^{132-134}$ It is important to note that the aim of these procedures is not complete correction of refractive error, but reduction in its magnitude. Also, anticipating a flattening effect of collagen crosslinking, undercorrection with photorefractive keratectomy by about $30 \%$ in both sphere and cylinder is targeted. Other approaches tried for visual improvement include two-step procedures, such as toric ICL implantation 6-12 months after collagen crosslinking in progressive keratoconus, and toric ICL implantation 6-10 months after Intacs implantation in keratoconic eyes with extreme myopia. ${ }^{135-137} \mathrm{An}$ inherent problem with combining different procedures is trying to judge the relative effect of each on the eye being treated, particularly given insufficient interval between procedures.

\section{Conclusion}

Centuries after the earliest descriptions of keratoconus, much about the etiology and pathogenesis of the condition remains an enigma. Significant strides have been made in early detection of the disease, as well as towards providing optimal optical and surgical correction for improving the quality of vision in affected patients. The past two decades, in particular, have seen exciting new developments promising to favorably alter the natural history of keratoconus for the first time. Scientific interest in the condition is bound to remain high in the foreseeable future for two major reasons. First, the impending threat of iatrogenic ectasia or unmasking of subclinical keratoconus dangles like the sword of Damocles over all refractive surgeons. Secondly, recent advancements have expanded the therapeutic options and exposed the potential for further innovations. Hopefully, this will also translate into safer and more effective treatments for patients.

\section{Disclosure}

The author reports no conflicts of interest in this work.

\section{References}

1. Grzybowski A, McGhee CN. The early history of keratoconus prior to Nottingham's landmark 1854 treatise on conical cornea: a review. Clin Exp Optom. 2013;96(2):140-145.
2. Nottingham J. Practical Observations on Conical Cornea. London, UK: Churchill; 1854.

3. McGhee CN. 2008 Sir Norman McAlister Gregg Lecture: 150 years of practical observations on the conical cornea - what have we learned? Clin Experiment Ophthalmol. 2009;37(2):160-176.

4. Li X. Longitudinal study of the normal eyes in unilateral keratoconus patients. Ophthalmology. 2004;111(3):440-446.

5. Klyce SD. Chasing the suspect: keratoconus. $B r J$ Ophthalmol. 2009;93(7):845-847.

6. Kennedy RH, Bourne WM, Dyer JA. A 48-year clinical and epidemiologic study of keratoconus. Am J Ophthalmol. 1986;101(3): 267-273.

7. Rabinowitz YS. Keratoconus. Surv Ophthalmol. 1998;42(4):297-319.

8. Pearson AR, Soneji B, Sarvananthan N, Sandford-Smith JH. Does ethnic origin influence the incidence or severity of keratoconus? Eye. 2000;14(4):625-628.

9. Georgiou T, Funnell CL, Cassels-Brown A, O'Conor R. Influence of ethnic origin on the incidence of keratoconus and associated atopic disease in Asians and white patients. Eye (Lond). 2004;18(4):379-383.

10. Nielsen K, Hjortdal J, Aagaard Nohr E, Ehlers N. Incidence and prevalence of keratoconus in Denmark. Acta Ophthalmol Scand. 2007;85(8): 890-892.

11. Wagner H, Barr JT, Zadnik K. Collaborative Longitudinal Evaluation of Keratoconus (CLEK) Study: methods and findings to date. Cont Lens Anterior Eye. 2007;30(4):223-232.

12. Rahi A, Davies P, Ruben M, Lobascher D, Menon J. Keratoconus and coexisting atopic disease. Br J Ophthalmol. 1977;61(12):761-764.

13. Gasset AR, Hinson WA, Frias JL. Keratoconus and atopic diseases. Ann Ophthalmol. 1978;10(8):991-994.

14. Bawazeer AM. Atopy and keratoconus: a multivariate analysis. $\mathrm{Br} \mathrm{J}$ Ophthalmol. 2000;84(8):834-836.

15. Totan Y, Hepşen IF, Cekiç O, Gündüz A, Aydin E. Incidence of keratoconus in subjects with vernal keratoconjunctivitis: a videokeratographic study. Ophthalmology. 2001;108(4):824-827.

16. Feder RS, Gan TJ. Noninflammatory ectatic disorders. In: Krachmer JH, Mannis MJ, Holland EJ, editors. Cornea: Fundamentals, Diagnosis and Management. Philadelphia, PA: Elsevier Mosby; 2005.

17. Beardsley TL, Foulks GN. An association of keratoconus and mitral valve prolapse. Ophthalmology. 1982;89(1):35-37.

18. Lichter H, Loya N, Sagie A, Cohen N. Keratoconus and mitral valve prolapse. Am J Ophthalmol. 2000;129(5):667-668.

19. Cullen JF, Butler HG. Mongolism (Down's syndrome) and keratoconus. Br J Ophthalmol. 1963;47(6):321-330.

20. Shapiro MB, France TD. The ocular features of Down's syndrome. Am J Ophthalmol. 1985;99(6):659-663.

21. Robertson I. Keratoconus and the Ehlers-Danlos syndrome: a new aspect of keratoconus. Med J Aust. 1975;1(18):571-573.

22. Woodward EG, Morris MT. Joint hypermobility in keratoconus. Ophthalmic Physiol Opt. 1990;10(4):360-362.

23. Nielsen K, Hjortdal J, Pihlmann M, Corydon TJ. Update on the keratoconus genetics. Acta Ophthalmol. 2012;91(2):106-113.

24. Gajecka M, Nowak D. The genetics of keratoconus. Middle East Afr J Ophthalmol. 2011;18(1):2.

25. Jun AS, Cope L, Speck C, et al. Subnormal cytokine profile in the tear fluid of keratoconus patients. PLoS One. 2011;6(1):e16437.

26. Balasubramanian SA, Pye DC, Willcox MD. Are proteinases the reason for keratoconus? Curr Eye Res. 2010;35(3):185-191.

27. Balasubramanian SA, Pye DC, Willcox MD. Levels of lactoferrin, secretory IgA and serum albumin in the tear film of people with keratoconus. Exp Eye Res. 2012;96(1):132-137.

28. Romero-Jiménez M, Santodomingo-Rubido J, Wolffsohn JS. Keratoconus: a review. Cont Lens Anterior Eye. 2010;33(4):157-166.

29. Klyce SD. Computer-assisted corneal topography. High-resolution graphic presentation and analysis of keratoscopy. Invest Ophthalmol Vis Sci. 1984;25(12):1426-1435.

30. Rabinowitz YS, McDonnell PJ. Computer-assisted corneal topography in keratoconus. Refract Corneal Surg. 1989;5(6):400-408. 
31. Maeda N, Klyce SD, Smolek MK, Thompson HW. Automated keratoconus screening with corneal topography analysis. Invest Ophthalmol Vis Sci. 1994;35(6):2749-2757.

32. Maeda N, Klyce SD, Smolek MK. Comparison of methods for detecting keratoconus using videokeratography. Arch Ophthalmol. 1995;113(7): $870-874$.

33. Rabinowitz YS. Videokeratographic indices to aid in screening for keratoconus. J Refract Surg. 1995;11(5):371-379.

34. Rabinowitz YS, Rasheed K. KISA\% index: a quantitative videokeratography algorithm embodying minimal topographic criteria for diagnosing keratoconus. J Cataract Refract Surg. 1999;25(10):1327-1335.

35. Li X, Yang H, Rabinowitz YS. Longitudinal study of keratoconus progression. Exp Eye Res. 2007;85(4):502-507.

36. Lim L, Wei RH, Chan WK, Tan DT. Evaluation of keratoconus in Asians: role of Orbscan II and Tomey TMS-2 corneal topography. Am J Ophthalmol. 2007;143(3):390-400.

37. Sahin A, Yildirim N, Basmak H. Two-year interval changes in Orbscan II topography in eyes with keratoconus. $J$ Cataract Refract Surg. 2008;34(8):1295-1299.

38. Quisling S, Sjoberg S, Zimmerman B, Goins K, Sutphin J. Comparison of Pentacam and Orbscan IIz on posterior curvature topography measurements in keratoconus eyes. Ophthalmology. 2006;113(9):1629-1632.

39. Ambrósio R Jr, Alonso RS, Luz A, Coca Velarde LG. Corneal-thickness spatial profile and corneal-volume distribution: Tomographic indices to detect keratoconus. J Cataract Refract Surg. 2006;32(11): 1851-1859.

40. Piñero DP, Alio JL, Alesón A, Vergara ME, Miranda M. Corneal volume, pachymetry, and correlation of anterior and posterior corneal shape in subclinical and different stages of clinical keratoconus. $J$ Cataract Refract Surg. 2010;36(5):814-825.

41. Uçakhan ÖÖ, Çetinkor V, Özkan M, Kanpolat A. Evaluation of Scheimpflug imaging parameters in subclinical keratoconus, keratoconus, and normal eyes. J Cataract Refract Surg. 2011;37(6):1116-1124.

42. Piñero DP, Nieto JC, Lopez-Miguel A. Characterization of corneal structure in keratoconus. $J$ Cataract Refract Surg. 2012;38(12): 2167-2183.

43. Muftuoglu O, Ayar O, Ozulken K, Ozyol E, Akıncı A. Posterior corneal elevation and back difference corneal elevation in diagnosing forme fruste keratoconus in the fellow eyes of unilateral keratoconus patients. $J$ Cataract Refract Surg. 2013;39(9):1348-1357.

44. Maeda N, Fujikado T, Kuroda T, et al. Wavefront aberrations measured with Hartmann-Shack sensor in patients with keratoconus. Ophthalmology. 2002;109(11):1996-2003.

45. Schweitzer C, Roberts CJ, Mahmoud AM, Colin J, Maurice-Tison S, Kerautret J. Screening of forme fruste keratoconus with the ocular response analyzer. Invest Ophthalmol Vis Sci. 2010;51(5):2403-2410.

46. Johnson RD, Nguyen MT, Lee N, Hamilton DR. Corneal biomechanical properties in normal, forme fruste keratoconus, and manifest keratoconus after statistical correction for potentially confounding factors. Cornea. 2011;30(5):516-523.

47. Fontes BM, Ambrósio R, Velarde GC, Nosé W. Ocular response analyzer measurements in keratoconus with normal central corneal thickness compared with matched normal control eyes. J Refract Surg. 2011;27(3):209-215.

48. Alio JL, Piñero DP, Alesón A, et al. Keratoconus-integrated characterization considering anterior corneal aberrations, internal astigmatism, and corneal biomechanics. J Cataract Refract Surg. 2011;37(3):552-568.

49. Sherwin T, Brookes NH. Morphological changes in keratoconus: pathology or pathogenesis. Clin Experiment Ophthalmol. 2004;32(2): 211-217.

50. Kaldawy RM, Wagner J, Ching S, Seigel GM. Evidence of apoptotic cell death in keratoconus. Cornea. 2002;21(2):206-209.

51. Sykakis E, Carley F, Irion L, Denton J, Hillarby MC. An in depth analysis of histopathological characteristics found in keratoconus. Pathology. 2012;44(3):234-239.

52. Patel DV, Ku JY, Johnson R, McGhee CN. Laser scanning in vivo confocal microscopy and quantitative aesthesiometry reveal decreased corneal innervation and sensation in keratoconus. Eye. 2008;23(3): $586-592$.
53. Mathew JH, Goosey JD, Bergmanson JP. Quantified histopathology of the keratoconic cornea. Optom Vis Sci. 2011;88(8):988-997.

54. Basu S, Reddy JC, Vaddavalli PK, Vemuganti GK, Sangwan VS. Longterm outcomes of penetrating keratoplasty for keratoconus with resolved corneal hydrops. Cornea. 2012;31(6):615-620.

55. Basu S, Vaddavalli PK, Vemuganti GK, Ali MH, Murthy SI. Anterior segment optical coherence tomography features of acute corneal hydrops. Cornea. 2012;31(5):479-485.

56. Weed KH, MacEwen CJ, McGhee CN. The Dundee University Scottish Keratoconus Study II: a prospective study of optical and surgical correction. Ophthalmic Physiol Opt. 2007;27(6):561-567.

57. Barnett M, Mannis MJ. Contact lenses in the management of keratoconus. Cornea. 2011;30(12):1510-1516.

58. Spoerl E, Huhle M, Seiler T. Induction of cross-links in corneal tissue. Exp Eye Res. 1998;66(1):97-103.

59. Spörl E, Schreiber J, Hellmund K, Seiler T. Untersuchungen zur verfestigung der hornhaut am kaninchen. [Studies on the stabilization of the cornea in rabbits] Ophthalmologe. 2000;97(3): 203-206. German.

60. Wollensak G, Spoerl E, Seiler T. Riboflavin/ultraviolet-A-induced collagen crosslinking for the treatment of keratoconus. $\mathrm{Am} \mathrm{J}$ Ophthalmol. 2003;135(5):620-627.

61. Raiskup-Wolf F, Hoyer A, Spoerl E, Pillunat LE. Collagen crosslinking with riboflavin and ultraviolet-A light in keratoconus: long-term results. J Cataract Refract Surg. 2008;34(5):796-801.

62. Caporossi A, Mazzotta C, Baiocchi S, Caporossi T. Long-term results of riboflavin ultraviolet a corneal collagen cross-linking for keratoconus in Italy: the Siena eye cross study. Am J Ophthalmol. 2010;149(4):585-593.

63. Koller T, Pajic B, Vinciguerra P, Seiler T. Flattening of the cornea after collagen crosslinking for keratoconus. J Cataract Refract Surg. 2011;37(8):1488-1492.

64. Asri D, Touboul D, Fournié P, et al. Corneal collagen crosslinking in progressive keratoconus: multicenter results from the French National Reference Center for Keratoconus. J Cataract Refract Surg. 2011;37(12):2137-2143.

65. Wittig-Silva C, Whiting M, Lamoureux E, Lindsay RG, Sullivan LJ, Snibson GR. A randomized controlled trial of corneal collagen crosslinking in progressive keratoconus: preliminary results. J Refract Surg. 2008;24(7):S720-S725.

66. Hersh PS, Greenstein SA, Fry KL. Corneal collagen crosslinking for keratoconus and corneal ectasia: one-year results. $J$ Cataract Refract Surg. 2011;37(1):149-160.

67. O’Brart DPS, Chan E, Samaras K, Patel P, Shah SP. A randomised, prospective study to investigate the efficacy of riboflavin/ultraviolet A $(370 \mathrm{~nm})$ corneal collagen cross-linkage to halt the progression of keratoconus. Br J Ophthalmol. 2011;95(11):1519-1524.

68. Jain R, Basu S, Garg P. Corneal collagen cross-linkage in keratoconus. Br J Ophthalmol. 2012;97(1):108-109.

69. Pollhammer M, Cursiefen C. Bacterial keratitis early after corneal crosslinking with riboflavin and ultraviolet-A. J Cataract Refract Surg. 2009;35(3):588-589.

70. Pérez-Santonja JJ, Artola A, Javaloy J, Alio JL, Abad JL. Microbial keratitis after corneal collagen crosslinking. $J$ Cataract Refract Surg. 2009;35(6):1138-1140.

71. Sharma N, Maharana P, Singh G, Titiyal JS. Pseudomonas keratitis after collagen crosslinking for keratoconus: case report and review of literature. J Cataract Refract Surg. 2010;36(3):517-520.

72. Garcia-Delpech S, Díaz-Llopis M, Udaondo P, Salom D. Fusarium keratitis 3 weeks after healed corneal cross-linking. J Refract Surg. 2010;26(12):994-995.

73. Rama P, Di Matteo F, Matuska S, Paganoni G, Spinelli A. Acanthamoeba keratitis with perforation after corneal crosslinking and bandage contact lens use. J Cataract Refract Surg. 2009;35(4):788-791.

74. Angunawela RI, Arnalich-Montiel F, Allan BD. Peripheral sterile corneal infiltrates and melting after collagen crosslinking for keratoconus. $J$ Cataract Refract Surg. 2009;35(3):606-607. 
75. Arora R, Jain P, Gupta D, Goyal JL. Sterile keratitis after corneal collagen crosslinking in a child. Cont Lens Anterior Eye. 2012;35(5):233-235.

76. Kymionis GD, Portaliou DM, Diakonis VF, Kounis GA, Panagopoulou SI, Grentzelos MA. Corneal collagen cross-linking with riboflavin and ultraviolet-a irradiation in patients with thin corneas. Am J Ophthalmol. 2012;153(1):24-28.

77. Spoerl E, Hoyer A, Pillunat LE, Raiskup F. Corneal cross-linking and safety issues. Open Ophthalmol J. 2011;5:14-16.

78. Gokhale NS. Corneal endothelial damage after collagen cross-linking treatment. Cornea. 2011;30(12):1495-1498.

79. Bagga B, Pahuja S, Murthy S, Sangwan VS. Endothelial failure after collagen cross-linking with riboflavin and UV-A: case report with literature review. Cornea. 2012;31(10):1197-1200.

80. Sharma A, Nottage JM, Mirchia K, Sharma R, Mohan K, Nirankari VS. Persistent corneal edema after collagen cross-linking for keratoconus. Am J Ophthalmol. 2012;154(6):922-926.

81. Hafezi F, Mrochen M, Iseli HP, Seiler T. Collagen crosslinking with ultraviolet $\mathrm{A}$ and hypoosmolar riboflavin solution in thin corneas. $J$ Cataract Refract Surg. 2009;35(4):621-624.

82. Leccisotti A, Islam T. Transepithelial corneal collagen cross-linking in keratoconus. J Refract Surg. 2010;26(12):942-948.

83. Spadea L, Mencucci R. Transepithelial corneal collagen cross-linking in ultrathin keratoconic corneas. Clin Ophthalmol. 2012;6:1785.

84. Koppen C, Wouters K, Mathysen D, Rozema J, Tassignon MJ. Refractive and topographic results of benzalkonium chloride-assisted transepithelial crosslinking. J Cataract Refract Surg. 2012;38(6):1000-1005.

85. Filippello M, Stagni E, O'Brart D. Transepithelial corneal collagen crosslinking: bilateral study. J Cataract Refract Surg. 2012;38(2): 283-291.

86. Rocha KM, Ramos-Esteban JC, Qian Y, Herekar S, Krueger RR. Comparative study of riboflavin-UVA cross-linking and "flash-linking" using surface wave elastometry. J Refract Surg. 2008;24(7):S748-S751.

87. Smiddy WE, Hamburg TR, Kracher GP, Stark WJ. Keratoconus. Contact lens or keratoplasty? Ophthalmology. 1988;95(4):487-492.

88. Sray WA, Cohen EJ, Rapuano CJ, Laibson PR. Factors associated with the need for penetrating keratoplasty in keratoconus. Cornea. 2002;21(8):784-786.

89. Gordon MO, Steger-May K, Szczotka-Flynn L, et al. Baseline factors predictive of incident penetrating keratoplasty in keratoconus. Am J Ophthalmol. 2006;142(6):923-930.

90. Sharif KW, Casey TA. Penetrating keratoplasty for keratoconus: complications and long-term success. Br J Ophthalmol. 1991;75(3): 142-146.

91. Buzard KA, Fundingsland BR. Corneal transplant for keratoconus: results in early and late disease. J Cataract Refract Surg.1997;23(3) 398-406.

92. Olson RJ, Pingree M, Ridges R, Lundergan ML, Alldredge C, Clinch TE. Penetrating keratoplasty for keratoconus: a long-term review of results and complications. J Cataract Refract Surg. 2000;26(7):987-991.

93. Javadi MA, Motlagh BF, Jafarinasab MR, et al. Outcomes of penetrating keratoplasty in keratoconus. Cornea. 2005;24(8):941-946.

94. Price FW, Whitson WE, Marks RG. Graft survival in four common groups of patients undergoing penetrating keratoplasty. Ophthalmology. 1991;98(3):322-328.

95. Pramanik S, Musch DC, Sutphin JE, Farjo AA. Extended long-term outcomes of penetrating keratoplasty for keratoconus. Ophthalmology. 2006;113(9): 1633-1638.

96. Williams KA, Lowe MT, Keane MC, Jones VJ, Loh RS, Coster DJ. The Australian Corneal Graft Registry 2012. Available from: http://ebaanz. org/doc/ACGR_2012_REPORT_COMPLETE.pdf. Accessed August 16, 2013.

97. Busin M, Zambianchi L, Arffa RC. Microkeratome-assisted lamellar keratoplasty for the surgical treatment of keratoconus. Ophthalmology. 2005;112(6):987-997.

98. Busin M, Scorcia V, Zambianchi L, Ponzin D. Outcomes from a modified microkeratome-assisted lamellar keratoplasty for keratoconus. Arch Ophthalmol. 2012;130(6):776-782.
99. Melles GR, Lander F, Rietveld FJ, Remeijer L, Beekhuis WH, Binder PS. A new surgical technique for deep stromal, anterior lamellar keratoplasty. Br J Ophthalmol. 1999;83(3):327-333.

100. Anwar M, Teichmann KD. Big-bubble technique to bare Descemet's membrane in anterior lamellar keratoplasty. J Cataract Refract Surg. 2002;28(3):398-403.

101. Basu S, Sangwan VS. Deep anterior lamellar keratoplasty for resolved hydrops. Cornea. 2011;30(9):1067.

102. Anwar M, Teichmann KD. Deep lamellar keratoplasty: surgical techniques for anterior lamellar keratoplasty with and without baring of Descemet's membrane. Cornea. 2002;21(4):374-383.

103. Sarnicola V, Toro P, Gentile D, Hannush SB. Descemetic DALK and predescemetic DALK: outcomes in 236 cases of keratoconus. Cornea. 2010;29(1):53-59.

104. Jones MNA, Armitage WJ, Ayliffe W, Larkin DF, Kaye SB; NHSBT Ocular Tissue Advisory Group and Contributing Ophthalmologists (OTAG Audit Study 5). Penetrating and deep anterior lamellar keratoplasty for keratoconus: a comparison of graft outcomes in the United kingdom. Invest Ophthalmol Vis Sci. 2009;50(12):5625-5629.

105. Han DCY, Mehta JS, Por YM, Htoon HM, Tan DT. Comparison of outcomes of lamellar keratoplasty and penetrating keratoplasty in keratoconus. Am J Ophthalmol. 2009;148(5):744-751.

106. Javadi MA, Feizi S, Yazdani S, Mirbabaee F. Deep anterior lamellar keratoplasty versus penetrating keratoplasty for keratoconus: a clinical trial. Cornea. 2010;29(4):365-371.

107. Kubaloglu A, Sari ES, Unal M, et al. Long-term results of deep anterior lamellar keratoplasty for the treatment of keratoconus. Am J Ophthalmol. 2011;151(5):760-767.

108. Reinhart WJ, Musch DC, Jacobs DS, Lee WB, Kaufman SC, Shtein RM. Deep anterior lamellar keratoplasty as an alternative to penetrating keratoplasty: a report by the American Academy of Ophthalmology. Ophthalmology. 2011;118(1):209-218.

109. Basu S, Vaddavalli PK, Ramappa M, Shah S, Murthy SI, Sangwan VS. Intracameral perfluoropropane gas in the treatment of acute corneal hydrops. Ophthalmology. 2011;118(5):934-939.

110. Basu S, Mukhopadhyay S. Acute corneal hydrops. Ophthalmology. 2012;119(10):2197-2197.

111. Piñero DP, Alio JL. Intracorneal ring segments in ectatic corneal disease - a review. Clin Experiment Ophthalmol. 2010;38(2): 154-167.

112. Rabinowitz YS. INTACS for keratoconus. Int Ophthalmol Clin. 2010;50(3):63-76.

113. Kamiya K, Shimizu K, Ando W, Asato Y, Fujisawa T. Phakic toric implantable collamer lens implantation for the correction of high myopic astigmatism in eyes with keratoconus. J Refract Surg. 2008;24(8): 840-842.

114. Alfonso JF, Palacios A, Montés-Micó R. Myopic phakic STAAR collamer posterior chamber intraocular lenses for keratoconus. J Refract Surg. 2008;24(9):867-874.

115. Kamiya K, Shimizu K, Kobashi H, et al. Clinical outcomes of posterior chamber toric phakic intraocular lens implantation for the correction of high myopic astigmatism in eyes with keratoconus: 6-month followup. Graefes Arch Clin Exp Ophthalmol. 2011;249(7): 1073-1080.

116. Hashemian SJ, Soleimani M, Foroutan A, Joshaghani M, Ghaempanah J, Jafari ME. Toric implantable collamer lens for high myopic astigmatism in keratoconic patients after six months. Clin Exp Optom. 2013;96(2):225-232.

117. Venter J. Artisan phakic intraocular lens in patients with keratoconus. $J$ Refract Surg. 2009;25(9):759-764.

118. Sedaghat M, Ansari-Astaneh MR, Zarei-Ghanavati M, Davis SW, Sikder S. Artisan iris-supported phakic IOL implantation in patients with keratoconus: a review of 16 eyes. $J$ Refract Surg. 2011;27(7): 489-493.

119. Izquierdo L Jr, Henriquez MA, McCarthy M. Artiflex phakic intraocular lens implantation after corneal collagen cross-linking in keratoconic eyes. J Refract Surg. 2011;27(7):482-487. 
120. Thebpatiphat N, Hammersmith KM, Rapuano CJ, Ayres BD, Cohen EJ. Cataract surgery in keratoconus. Eye Contact Lens. 2007;33(5):244-246.

121. Bourges JL. Cataract surgery in keratoconus with irregular astigmatism. In: Goggin M, editor. Astigmatism - Optics, Physiology and Management. InTech; 2012. Available from: http://www.intechopen. com/books/astigmatism-optics-physiology-and-management/ cataract-surgery-on-irregular-astigmatism-of-keratoconus. Accessed August 16, 2013.

122. Jain AK, Bansal R, Nawani N, John T. AcrySof toric IOL implantation in phacosurgery in keratoconus patient with cataract. Techniques in Ophthalmology. 2009;7(4):131.

123. Visser N, Gast ST, Bauer NJ, Nuijts RM. Cataract surgery with toric intraocular lens implantation in keratoconus: a case report. Cornea. 2011;30(6):720-723.

124. Bilgihan K, Ozdek SC, Konuk O, Akata F, Hasanreisoglu B. Results of photorefractive keratectomy in keratoconus suspects at 4 years. $J$ Refract Surg. 2000;16(4):438-443.

125. Bahar I, Levinger S, Kremer I. Wavefront-supported photorefractive keratectomy with the Bausch and Lomb Zyoptix in patients with myopic astigmatism and suspected keratoconus. J Refract Surg. 2006;22(6):533-538.

126. Cennamo G, Intravaja A, Boccuzzi D, Marotta G, Cennamo G. Treatment of keratoconus by topography-guided customized photorefractive keratectomy: two-year follow-up study. J Refract Surg. 2008;24(2):145-149.

127. Guedj M, Saad A, Audureau E, Gatinel D. Photorefractive keratectomy in patients with suspected keratoconus: five-year follow-up. J Cataract Refract Surg. 2013;39(1):66-73.

128. Ormonde S. Refractive surgery for keratoconus. Clin Exp Optom. 2013;96(2):173-182.
129. Kato N, Toda I, Kawakita T, Sakai C, Tsubota K. Topography-guided conductive keratoplasty: treatment for advanced keratoconus. Am J Ophthalmol. 2010;150(4):481-489.

130. Basu S, Sangwan VS. Efficacy and safety of conductive keratoplasty in keratoconus. Am J Ophthalmol. 2011;151(4):735.

131. Kanellopoulos AJ. Comparison of sequential vs same-day simultaneous collagen cross-linking and topography-guided PRK for treatment of keratoconus. J Refract Surg. 2009;25(9):S812.

132. Kymionis GD, Kontadakis GA, Kounis GA, et al. Simultaneous topography-guided PRK followed by corneal collagen cross-linking for keratoconus. J Refract Surg. 2009;25(9):S807-S811.

133. Krueger RR, Kanellopoulos AJ. Stability of simultaneous topographyguided photorefractive keratectomy and riboflavin/UVA cross-linking for progressive keratoconus: case reports. J Refract Surg. 2010;26(10): S827-S832.

134. Kymionis GD, Portaliou DM, Kounis GA, Limnopoulou AN, Kontadakis GA, Grentzelos MA. Simultaneous topography-guided photorefractive keratectomy followed by corneal collagen cross-linking for keratoconus. Am J Ophthalmol. 2011;152(5):748-755.

135. Kymionis GD, Grentzelos MA, Karavitaki AE, Zotta P, Yoo SH, Pallikaris IG. Combined corneal collagen cross-linking and posterior chamber toric implantable collamer lens implantation for keratoconus. Ophthalmic Surg Lasers Imaging. 2011;42:e22-e25.

136. Fadlallah A, Dirani A, El Rami H, Cherfane G, Jarade E. Safety and visual outcome of Visian toric ICL implantation after corneal collagen cross-linking in keratoconus. J Refract Surg. 2013;29(2):84-89.

137. Coskunseven E, Onder M, Kymionis GD, et al. Combined Intacs and posterior chamber toric implantable collamer lens implantation for keratoconic patients with extreme myopia. Am J Ophthalmol. 2007; 144(3):387-389.

\section{Clinical Ophthalmology}

\section{Publish your work in this journal}

Clinical Ophthalmology is an international, peer-reviewed journal covering all subspecialties within ophthalmology. Key topics include: Optometry; Visual science; Pharmacology and drug therapy in eye diseases; Basic Sciences; Primary and Secondary eye care; Patient Safety and Quality of Care Improvements. This journal is indexed on Submit your manuscript here: http://www.dovepress.com/clinical-ophthalmology-journal

\section{Dovepress}

PubMed Central and CAS, and is the official journal of The Society of Clinical Ophthalmology (SCO). The manuscript management system is completely online and includes a very quick and fair peer-review system, which is all easy to use. Visit http://www.dovepress.com/ testimonials.php to read real quotes from published authors. 